\title{
Identification of 14 new glucokinase mutations and description of the clinical profile of 42 MODY-2 families
}

\author{
G.Velho ${ }^{1}$, H .B lanché ${ }^{2}$, M.Vaxillaire ${ }^{3}$, C.B ellanné-Chantelot' ${ }^{2}$, V.C.Pardini' ${ }^{4}$, J.Timsit ${ }^{5}$, Ph. Passa ${ }^{6}$, I.D eschamps ${ }^{7}$,

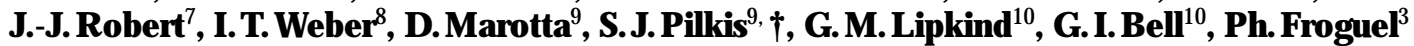 \\ ${ }^{1}$ IN SE R M U -358, H ôpital Saint L ouis, Paris, France \\ ${ }^{2}$ Fondation J ean D ausset-CE PH , Paris, France \\ ${ }^{3}$ CNR S E P-10, Institut Pasteur et CHU de Lille, Lille, France \\ ${ }^{4}$ CE PE N, Belo Horizonte, $M G, B$ razil \\ ${ }^{5}$ Service d'I mmunologie Clinique, $\mathrm{H}$ ôpital N ecker-E nfants $\mathrm{M}$ alades, Paris, France \\ ${ }^{6}$ Service d'E ndocrinologie et D iabétologie, H ôpital Saint L ouis, Paris, France \\ ${ }^{7}$ I N SE R M U -30, H ôpital N ecker-E nfants M alades, Paris, France \\ ${ }^{8}$ D epartment of P harmacology, J efferson Cancer Institute, Thomas J efferson U niversity, Philadelphia, Pennsylvania, U SA \\ ${ }^{9}$ D epartment of B iochemistry, U niversity of M innesota, M inneapolis, M innesota, U SA \\ ${ }^{10} \mathrm{H}$ oward $\mathrm{H}$ ughes $\mathrm{M}$ edical Institute and D epartments of B iochemistry and M olecular B iology and M edicine, \\ The U niversity of Chicago, Chicago, Illinois
}

Summary Mutations in glucokinase are associated with defects in insulin secretion and hepatic glycogen synthesis resulting in mild chronic hyperglycaemia, impaired glucose tolerance or diabetes mellitus. We screened members of 35 families with features of maturity-onset diabetes of the young for mutations in the glucokinase gene and found 16 different mutations. They included 14 new mutations in the glucokinase gene: 9 missense mutations (A 53S, G 80A, H 137R, T 168P, M 210T, C213R, V 226M, S336L and $V$ 367M ); 2 nonsense mutations (E 248X and S360X); a deletion of one nucleotide resulting in a frameshift ( $V$ 401del 1); a substitution of a conserved nucleotide at a splice acceptor site ( $\mathrm{L} 122-1 \mathrm{G} \rightarrow \mathrm{T}$ ); and a 10 base pair deletion that removed the $\mathrm{G} T$ of the splice donor site and the following eight nucleotides (K $161+2$ del10). I n addition, we found two previously identified mutations: R 186X and G 261R. Study of 260 subjects with glucokinase-deficient hyperglycaemia from 42 families with 36 different GCK mutations made it possible to define the clinical profile of this subtype of non-insulin-dependent diabetes mellitus (NIDDM). H yperglycaemia due to glucokinase deficiency is often mild (fewer than $50 \%$ of subjects have overt diabetes) and is evident during the early years of life. D espite the long duration of hyperglycaemia, glucokinase-deficient subjects have a low prevalence of micro- and macro-vascular complications of diabetes. O besity, arterial hypertension and dyslipidaemia are also uncommon in this form of NID D M . [D iabetologia (1997) 40: 217-224]

Keywords Diabetes mellitus, MODY, glucokinase mutations, insulin secretion, genetics.
$M$ aturity-onset diabetes of the young (MODY) is a form of non-insulin-dependent diabetes mellitus (NIDDM) characterized by early onset, usually

† D eceased

R eceived: 9July 1996 and in revised form: 160 ctober 1996

Corresponding author: D r. G.Velho, IN SE R M U -358, H ôpital Saint L ouis, 1 A venue Claude Vellefaux, 75010 Paris, France A bbreviations: NID D M, N on-insulin-dependent diabetes mellitus; M ODY, maturity-onset diabetes of the young; G CK, glucokinase gene; IG T, impaired glucose tolerance; ID D M , insulin-dependent diabetes mellitus; bp, base pair. before 25 years of age and often in adolescence, and by autosomal dominant inheritance [1]. A lthough commonly thought to be a relatively rare form of NIDDM, recent studies suggest that it may not be that uncommon and $2-5 \%$ of patients with NIDDM may in fact have MODY [2]. M utations in genes on chromosomes 20, 7 and 12, designated MODY1, MODY 2/glucokinase (GCK) and MODY 3, respectively, can cause this form of diabetes [3-5]. M oreover, there are likely to be additional MODY genes since there are families in which M ODY does not cosegregate with markers tightly linked to the three known MODY loci [5]. 
Table 1. New glucokinase mutations in M O DY families

\begin{tabular}{|c|c|c|c|c|c|}
\hline \multirow[t]{2}{*}{ Family } & \multicolumn{2}{|c|}{ Location of mutation } & \multirow[t]{2}{*}{ Nucleotide change } & \multirow[t]{2}{*}{ A mino acid change } & \multirow[t]{2}{*}{ D esignation } \\
\hline & Exon & Codon & & & \\
\hline $\begin{array}{l}\text { F585 } \\
\text { F557 } \\
\text { F540 } \\
\text { GF } \\
\text { F553 } \\
\text { F587 } \\
\text { HO } \\
\text { F586 } \\
\text { F583 } \\
\text { F541 } \\
\text { LZ } \\
\text { F588 } \\
\text { BO } \\
\text { F630 } \\
\text { F629 } \\
\text { SA }\end{array}$ & $\begin{array}{l}2 \\
3 \\
\text { intron } 3 \\
4 \\
\text { intron } 4 \\
5 \\
5 \\
6 \\
6 \\
6 \\
7 \\
7 \\
8 \\
9 \\
9 \\
9\end{array}$ & $\begin{array}{r}53 \\
80 \\
122 \\
137 \\
161 \\
168 \\
186 \\
210 \\
213 \\
226 \\
248 \\
261 \\
336 \\
360 \\
367 \\
401\end{array}$ & $\begin{array}{l}\text { GCC } \rightarrow \text { TCC } \\
\text { GGT } \rightarrow \text { GCT } \\
\text { A } \rightarrow \text { A T at splice acceptor site } \\
\text { CA T } \rightarrow \text { CG T } \\
\text { Del T of GT at splice donor site and } 9 \text { bp }^{a} \\
\text { ACC } \rightarrow \text { CCC } \\
\text { CGA } \rightarrow \text { TGA } \\
\text { ATG } \rightarrow \text { ACG } \\
\text { TGC } \rightarrow \text { CGC } \\
\text { GTG } \rightarrow \text { ATG } \\
\text { GAG } \rightarrow \text { TAG } \\
\text { GGG } \rightarrow \text { AGG } \\
\text { TCG } \rightarrow \text { TTG } \\
\text { TCG } \rightarrow \text { TA G } \\
\text { GTG } \rightarrow \text { ATG } \\
\text { GTA } \rightarrow \text { TA } / A\end{array}$ & $\begin{array}{l}\text { A la } \rightarrow \text { Ser } \\
\text { G ly } \rightarrow \text { A la } \\
\text { H is } \rightarrow \text { A rg } \\
\text { Thr } \rightarrow \text { Pro } \\
\text { A rg } \rightarrow \text { Stop (OP) } \\
\text { M et } \rightarrow \text { Thr } \\
\text { Cys } \rightarrow \text { A rg } \\
\text { Val } \rightarrow \text { M et } \\
\text { G lu } \rightarrow \text { Stop (A M ) } \\
\text { G ly } \rightarrow \text { A rg } \\
\text { Ser } \rightarrow \text { Leu } \\
\text { Ser } \rightarrow \text { Stop (A M ) } \\
\text { Val } \rightarrow \text { M et } \\
\text { Val } \rightarrow \text { Stop (OC) }\end{array}$ & $\begin{array}{l}\text { A 53S } \\
\text { G 80A } \\
\text { L 122-1G } \rightarrow \text { T } \\
\text { H 137R } \\
\text { K 161 + 1del10 } \\
\text { T 168P } \\
\text { R 186X } \\
\text { M 210T } \\
\text { C 213R } \\
\text { V 226M } \\
\text { E 248X } \\
\text { G 261R } \\
\text { S336L } \\
\text { S360X } \\
\text { V 367M } \\
\text { V 401del1 }\end{array}$ \\
\hline
\end{tabular}

a Sequence of mutation at splice donor site in family F553: G [T G G G CCG G GT] G GA G G G G CA $\rightarrow$ G G GA G G G CA The three classes of stop codons are amber (A M), ocher (OC) and opal (OP)

Mutations in the glucokinase gene are the most common cause of MODY in France with approximately $50 \%$ of subjects with MODY having mutations in this gene [4]. These subjects are often characterized by mild persistent fasting and postprandial hyperglycaemia. Clinical studies have shown that patients with glucokinase-deficient diabetes have a defect in glucose-stimulated insulin secretion with a rightward shift in the dose-response curve relating glucose concentration and rate of insulin secretion $[6,7]$. This defect results from impaired sensitivity of pancreatic beta cells to glucose as a consequence of decreased glucokinase activity in these cells. G lucokinase-deficient subjects also exhibit a reduction in postprandial hepatic glycogen synthesis and increased rates of gluconeogenesis following meals [8]. A Ithough subjects with GCK mutations may present with peripheral insulin resistance, the decreased insulin sensitivity appears to be secondary to the chronic hyperglycaemia [9].

In this report, we describe 16 families, 14 of French and 2 of B razilian ancestry, in which MODY results from mutations in GCK. Fourteen of the 16 mutations identified in these families have not been previously described. The study of 260 glucokinase-deficient subjects and 341 unaffected relatives from 42 families with 36 different GCK mutations [4, 10, 11 and this report] provide a clinical profile of this subtype of NIDDM.

\section{Subjects and methods}

Subjects. Probands of 35 families were studied, 31 of which were of French and 4 of B razilian ancestry. These subjects were seen by one of us at the outpatient clinics, or referred to us by their doctors with a clinical diagnosis of M ODY, including onset before 25 years of age and familial NID DM consistent with an autosomal dominant inheritance. Clinical data were obtained for each available member $(n=115)$ of the 16 families with a GCK mutation, during the course of a standard clinical examination performed either by one of us or by the subject's personal physician. Neurological history was taken and a physical examination performed focussing on symptoms and signs of distal symmetric sensorimotor polyneuropathy and autonomic neuropathy. Eye fundus examination was performed by the subject's personal ophthalmologist. Evidence for nephropathy was based on the presence of proteinuria tested by strips (lower limit of detection: 0,025$0,03 \mathrm{~g} / \mathrm{l}$ ). Subjects who were not overtly diabetic underwent an oral glucose tolerance test (OGTT) and a diagnosis of diabetes or impaired glucose tolerance (IGT) was made according to the criteria of the World Health Organization [12]: diabetes, fasting plasma glucose level greater than $7.8 \mathrm{mmol} / \mathrm{l}$ or 2 -h post oral glucose load greater than $11.1 \mathrm{mmol} / /$; and IG T, $2 \mathrm{~h}$ post oral glucose load greater than $7.8 \mathrm{mmol} / \mathrm{l}$. Subjects were considered to have mild fasting hyperglycaemia if they had a fasting plasma glucose level between 6.1 and $7.7 \mathrm{mmol} / \mathrm{l}$ on two separate occasions.

Screening for mutations in the glucokinase gene. M utations in GCK were identified by single-strand conformational polymorphism analysis and sequencing of bands with abnormal mobility as previously described [11, 13, 14].

\section{Statistical analysis}

R esults are expressed as means \pm SD unless otherwise stated. The Shapiro-Wilk W-test was used to test the G aussian distribution of clinical and biological parameters. G roup differences were assessed with Student's two-tailed unpaired t-test, using log-transformed data when appropriate. Qualitative traits were analysed using a contingency table. Statistics were performed with the JMP software (SA S Institute, Cary, N.C., USA ). 


\section{Results}

I dentification of mutations in the G CK gene. Fourteen new and two previously described mutations were identified (Table 1) in 16 families (Fig. 1), out of the 35 MODY families. The new mutations included nine missense mutations (A 53S, G80A, H 137R, T168P, M 210T, C213R, V 226M , S336L and V 367M), two nonsense mutations (E 248X and S360X), a deletion of one nucleotide resulting in a frameshift (V 401del1), a substitution of a conserved nucleotide at a splice acceptor site ( $122-1 G \rightarrow T$ ), and a 20 base pair (bp) deletion that removed the GT of the splice donor site and the following eight nucleotides (K $161+2$ del 10). The two previously identified mutations were R 186X and G 261R. The R 186X mutation has been found in one other French family [4], a Japanese family [15], and a black A frican family from the Congo [11]. The G 261R mutation has been found in two other French families [4] and a Japanese family [16].

A vailable family members were screened for the presence of the mutation identified in the proband, and in each case the mutation was present in all subjects with hyperglycaemia and in none of the normoglycaemic relatives, except for families SA and F553. In family SA, the V401dell mutation was not detected in one of the proband's sisters (Fig. 1; II/36) or mother (I/35), both of whom presented with obesity and late age-of-onset NIDDM. No DNA or clinical data were available for the proband's deceased father. In family F553, the $\mathrm{K} 161+1$ del 10 mutation was also detected in a normoglycaemic 4-year-old child (III/3924). In family F540, the L 122-1G $\rightarrow$ T mutation was detected in all subjects with MODY, and in the proband's brother (III/3588), a 13-yearold boy with a typical history of autoimmune insulindependent diabetes mellitus (IDDM). Diagnosis of IDDM was established at the age of 4 years by the presence of ketoacidosis and strongly positive isletcell antibodies. The observation in this child of an HLA DRB 1*04-13 genotype and a GCK mutation indicates that he had genetic susceptibility both to IDDM (allele 04) and MODY. O nly the proband was available for study in families F585, F586 and $\mathrm{HO}$, and only the proband and her mother in family $B O$. The H 137R mutation found in family $G F$ was observed in six hyperglycaemic subjects and four subjects for whom there was no information on glucose tolerance status. In the L Z family, the E 248X mutation was found in the proband and three of his sons but was not detected in his parents or any of his siblings, all of whom were normoglycaemic. Based on the genotyping results with other polymorphic markers, there was no evidence for nonpaternity in the $\mathrm{LZ}$ family suggesting that the $\mathrm{E} 248 \mathrm{X}$ mutation arose de novo. This is the second example of a de novo mutation in GCK that we have observed in our studies of
42 MODY families with glucokinase deficiency, the first being R $36 \mathrm{~W}$ in family F 547 [11]. B oth of these mutations occur within the context of a $\mathrm{CpG}$ dinucleotide, a hot spot for nucleotide substitutions in mammalian genes [17].

Clinical profile of glucokinase-deficient NIDDM. We have now studied 260 glucokinase-deficient subjects from 42 families with 36 different mutations (Table 2). They are characterized by a relatively mild form of diabetes, and in this large group, $42 \%$ have overt diabetes, $24 \%$ IGT, 31\% mild fasting hyperglycaemia, and $3 \%$ normal glucose tolerance. Half of the subjects with normal glucose tolerance are children younger than 5 years, while the other half, aged 19 to 57 years, have had documented episodes of hyperglycaemia (pregnancy, steroid therapy). These data indicate that GCK mutations are highly penetrant.

The diagnosis of hyperglycaemia in the majority of the subjects was fortuitous, most often during the course of a routine check-up (school, military service, work), prospective testing because of a strong family history of diabetes, or the presence of gestational-onset diabetes. The average age at diagnosis of chronic hyperglycaemia was $25 \pm 17$ years. Fiftysix percent of the subjects were diagnosed before the age of 25 years. However, a decrease in the mean age of diagnosis was observed in consecutive generations $(46 \pm 16$ years in patients older than 50 years, $26 \pm 9$ years in those aged $25-50$ years, and $10 \pm 5$ years in those aged less than 25 years), suggesting that this parameter might have suffered ascertainment bias in the older generations. Prospective studies in family members younger than 25 years show that approximately $90 \%$ of affected individuals present with hyperglycaemia before the age of 13 years. Furthermore, mild hyperglycaemia can be observed in infants as young as 12 months, suggesting that this condition may be present at birth. These observations are in agreement with reports showing that NIDDM with late age of onset is not associated with mutations in the coding regions of GCK [10, 18].

The prevalence of late complications of diabetes in 25 of the families studied here have been reported previously [19]. In the 42 families that we have now studied, proliferative retinopathy has been observed in less than $4 \%$ of the glucokinase-deficient subjects with hyperglycaemia of more than 5 years duration, while proteinuria was detected in $6 \%$, and peripheral neuropathy in $4 \%$ of these subjects. Obesity (BMI $\geq 27 \mathrm{~kg} / \mathrm{m}^{2}$ ) was present in less than $10 \%$ of subjects at diagnosis of hyperglycaemia and hypertension was observed in less than $15 \%$ of the glucokinase-deficient subjects older than 35 years. A low prevalence of dyslipidaemia was also observed: high triglycerides (> $1.8 \mathrm{mmol} / \mathrm{l}): 5.8 \%$; high LDL 


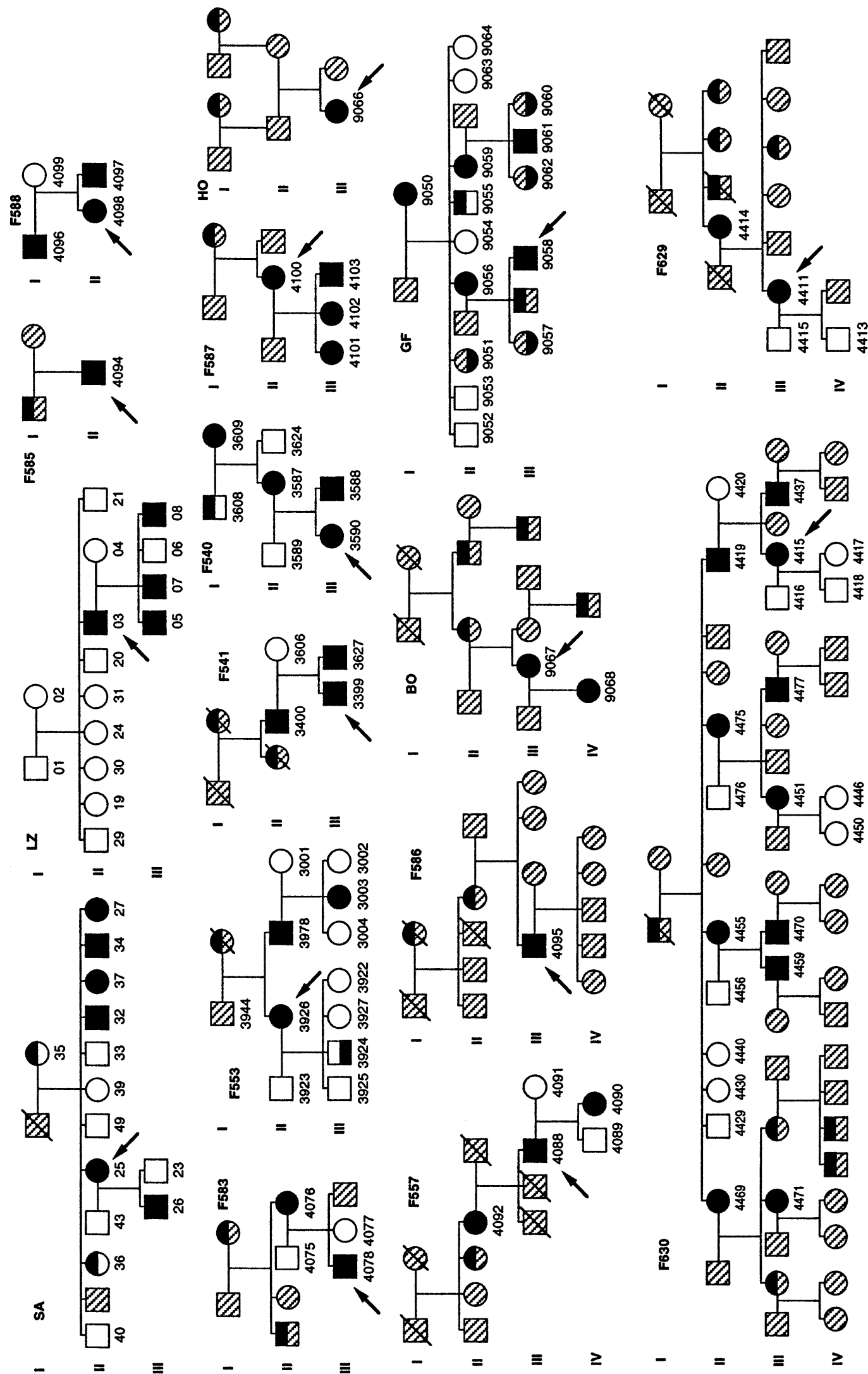

Fig. 1. Family trees of 16 pedigrees with glucokinase mutations $\quad \square$ GCK mutation; $\boldsymbol{H}$ yperglycaemia; $\square$ Wild type GCK and and MODY. Kindreds F540, F541, F553, F557, F583, F585, F586, F587, F588, GF, H O, B O, F629 and F630 are of French ancestry, and kindreds $S A$ and $L Z$ of $B$ razilian ancestry. A $n$ arrow indicates the proband in each family. 
Table 2. Clinical and biological profile of family members

\begin{tabular}{|c|c|c|c|}
\hline & Glucokinase-deficient subjects & U naffected relatives ${ }^{a}$ & p value \\
\hline M en/women & $128 / 132$ & $167 / 174$ & 0.95 \\
\hline A ge (years) & $36 \pm 21(2-96)^{b}$ & $33 \pm 19(1-83)$ & 0.14 \\
\hline A ge at diagnosis (years) & $25 \pm 17(1-80)^{c}$ & - & - \\
\hline B ody mass index $\left(\mathrm{kg} / \mathrm{m}^{2}\right)$ & $22.0 \pm 4.1$ & $22.1 \pm 4.3$ & 0.94 \\
\hline Systolic blood pressure $(\mathrm{mm} \mathrm{H} \mathrm{g})$ & $125 \pm 17$ & $123 \pm 17$ & 0.39 \\
\hline D iastolic blood pressure $(\mathrm{mm} \mathrm{H} g)$ & $71 \pm 11$ & $70 \pm 13$ & 0.16 \\
\hline Fasting insulin ( $\mathrm{pmol} / \mathrm{l})$ & $66 \pm 42$ & $60 \pm 48$ & 0.34 \\
\hline Fasting insulin/glucose ( $\mathrm{pmol} / \mathrm{mmol})$ & $8.70 \pm 5.52$ & $11.94 \pm 9.6$ & 0.002 \\
\hline 2-h Insulin ( $\mathrm{pmol} / \mathrm{l})$ & $174 \pm 150$ & $198 \pm 180$ & 0.25 \\
\hline 2-h Insulin/glucose ( $\mathrm{pmol} / \mathrm{mmol}$ ) & $18.66 \pm 13.02$ & $37.56 \pm 32.10$ & 0.0001 \\
\hline Creatinine $(\mu \mathrm{mol} / \mathrm{l})$ & $83 \pm 19$ & $80 \pm 19$ & 0.24 \\
\hline Triglycerides (mmol/l) & $0.97 \pm 0.54$ & $1.01 \pm 0.60$ & $0.39^{d}$ \\
\hline Total cholesterol (mmol/l) & $5.49 \pm 1.19$ & $5.39 \pm 1.23$ & $0.19^{d}$ \\
\hline $\mathrm{Lp}(\mathrm{a})(\mathrm{mg} \%)$ & $25.5 \pm 20.0$ & $27.5 \pm 21.5$ & $0.37^{d}$ \\
\hline
\end{tabular}

$D$ ata expressed as mean \pm SD and (range). R esults partially reported in references $[9,19]$.

a Mutation negative, normo-glucotolerant first-degree relatives;

b age distribution; younger than 25 years: 93 (39\%); between 25 and 45 years: $74(31 \%$ ); older than 45 years: $73(30 \%)$; c age of diagnosis distribution: < 25 years: $142(56 \%) ; 25$ to 45 years: $81(32 \%)$; > 45 years: $29(12 \%)$;

d age-adjusted comparisons.

2-h glucose and insulin are values during an oral glucose tolerance test; other biological parameters are fasting values

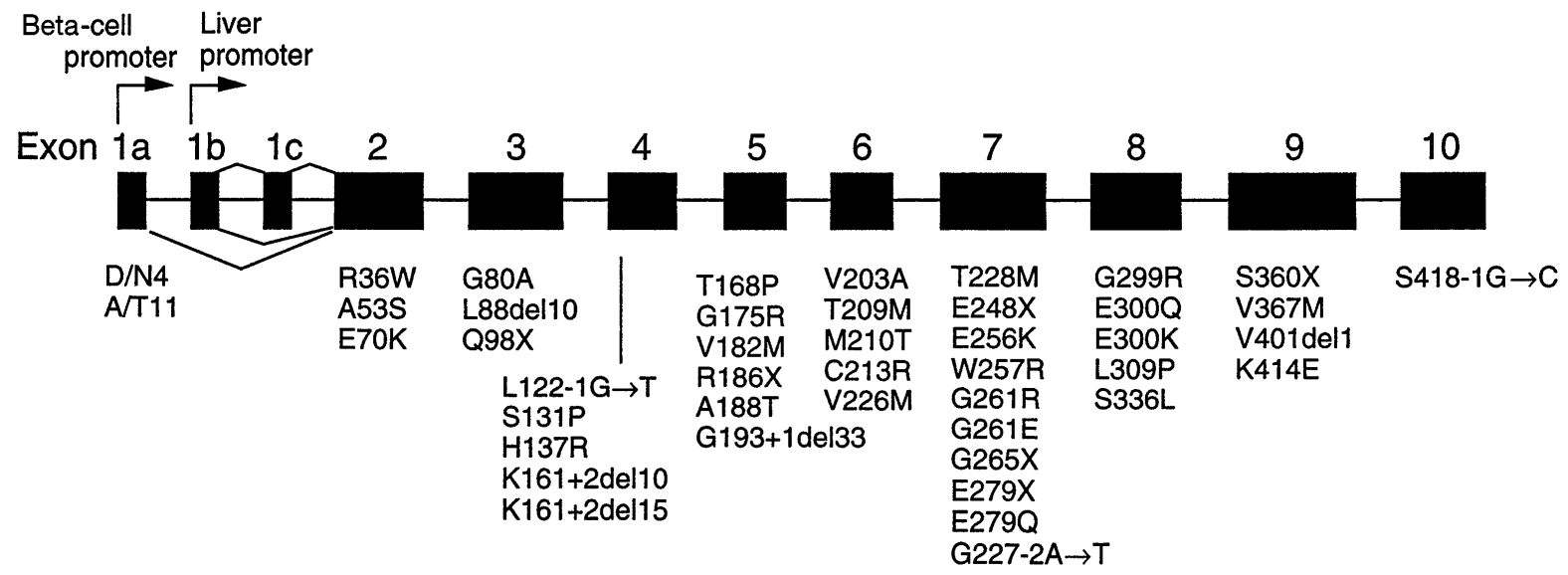

Fig. 2. Glucokinase mutations found in subjects with diabetes mellitus $[4,10,11,15,16,21,23-25,27$, and this report]. The exon-intron organization of the human glucokinase gene is shown and the mutations found in each exon noted. A mino acid residues are numbered as in the beta-cell form of human glucokinase. The two amino acid polymorphisms in the unique $\mathrm{NH}_{2}$-terminal portion of beta-cell glucokinase which is encoded by exon $1 \mathrm{a}$ are indicated: $A \operatorname{sn} / \mathrm{G} \ln 4(\mathrm{D} / \mathrm{N} 4)$ and $A$ la/ Thr 11 ( $\mathrm{A} / \mathrm{T} 11)$

cholesterol (> $4.9 \mathrm{mmol} / \mathrm{l}): 5.7 \%$; low HDL cholesterol $(<0.8 \mathrm{mmol} / \mathrm{l}): 1 \%$; low apoprotein A 1 levels (<130 mg/ml): $6 \%$; high apoprotein B (>130 mg/ $\mathrm{ml}): 18 \%$; and high lipoprotein (a) $(>30 \mathrm{mg} / \mathrm{ml})$ : $19 \%$.

\section{Discussion}

Mutations in GCK are the most common cause of MODY identified to date. Forty-two different mutations and two amino acid polymorphism have now been reported (Fig. 2). They have been found in subjects of many different racial and ethnic backgrounds including Caucasians (B razil [this report], France [4, 10, 11], I taly [20], Sweden [21], Switzerland [22], U nited Kingdom [23], and U nited States [24]), A sians (Japan [15, 16, 25]), blacks (Congo [11]), and admixed populations (A frican-A merican [21, 26] and Puerto Rican [24]). The majority of the mutations identified to date have been described in only a single family suggesting that the present list is not exhaustive and that new mutations will continue to be found. 


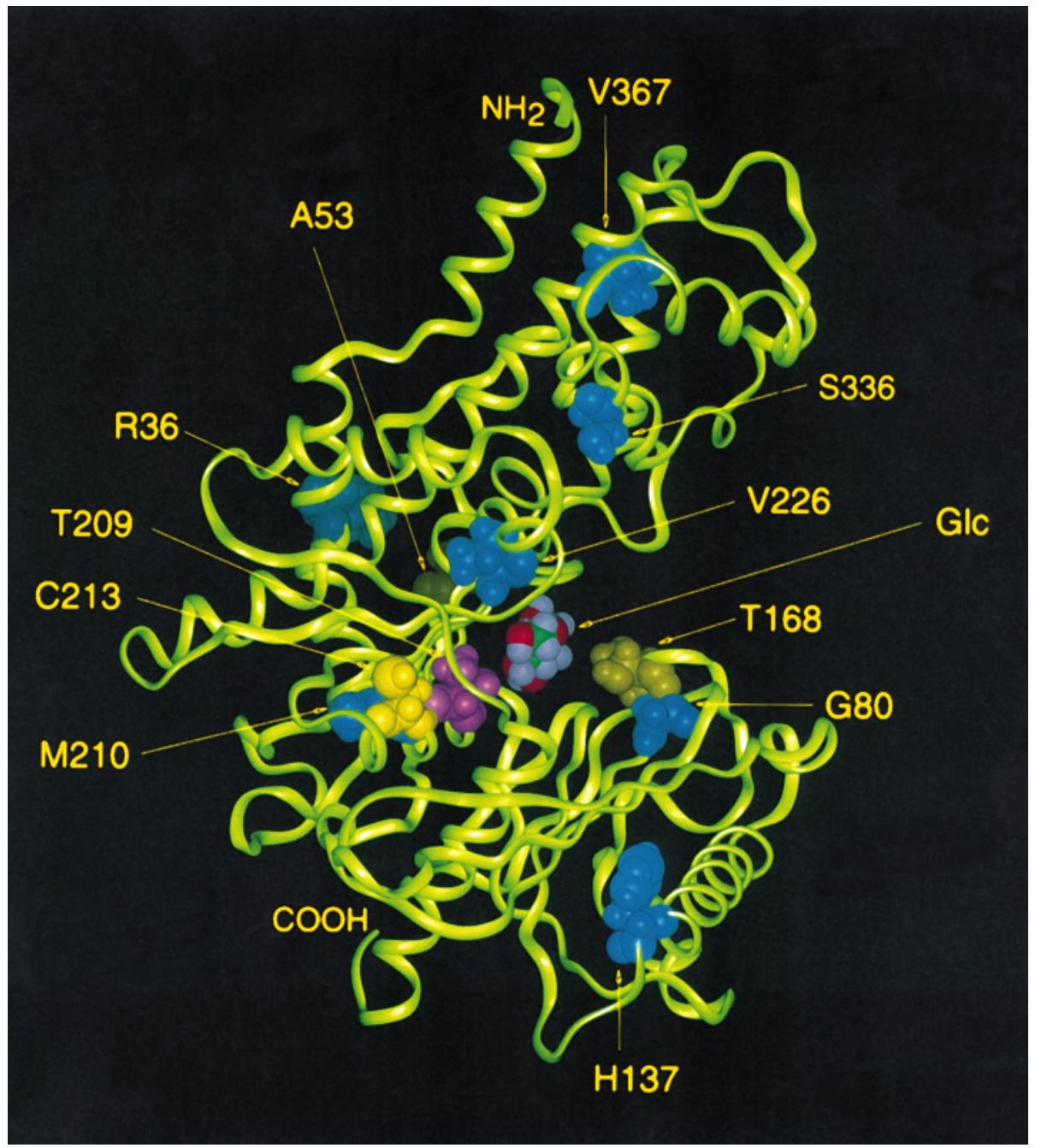

Fig. 3. M odel of the human beta-cell form of glucokinase with a molecule of glucose in the active site cleft. The alpha-carbon backbone of glucokinase is represented as a ribbon and the locations of amino acid residues that are the site of missense mutations are shown by space-filling models in blue, green, pink and yellow. A space-filling model of glucose ( $G I C$ ) in the active site cleft is shown with the individual atoms indicated: green, carbon; red, oxygen; and grey, hydrogen. A mino acid residues are noted by their singleletter abbreviation and residue number. This model was built in the Insight graphic environment (B iosym Technologies, Inc., San D iego, Calif., U SA )
Those mutations found in more than one family include V 182M (two French families [4]), R 186X (two French [11 and this report], one Japanese [15], and one Black-A frican family [11]), A 188T (one Japanese [25] and one Italian family [20]), V 203A (one French [4] and four Swiss families [22] suggesting a possible founder effect in Switzerland), G 261R (three French [4 and this report] and one Japanese family [16]), E 279Q (two A frican-A merican families [21]), and G 299R (two British families with a possible founder effect in 0 xfordshire [23]).

O ur previous studies have shown that missense mutations have variable effects on glucokinase activity ranging from a small change in affinity for glucose to complete inactivity [21, 27-29]. B ased on a model of the structure of human beta-cell glucokinase [30], we have observed that the known missense mutations fall into three main categories: mutations of conserved active site residues - these generally have a drastic effect on catalytic activity; mutations predicted to distort the enzyme structure - these tend to show reduced activity; and mutations of surface residues that eliminate conserved interactions with other residues and may reduce the stability of the structure or affect the conformational change that is observed on binding of glucose - these often show a small reduction in activity. In addition to affecting enzyme activity or stability [21,27,31], mutations may alter the interaction of glucokinase with other proteins such as the glucokinase regulatory protein [32].

Based on these results, we can consider the possible effects on activity of the nine new missense mutations identified during the course of this study. The mutations G $80 \mathrm{~A}$, T 168P, M 210T and V 226M are predicted to alter residues in or near the active site cleft (Fig. 3). These mutations are expected to greatly reduce catalytic activity. The mutation C213R is predicted to result in distortion of the glucokinase structure due to the introduction of a large A rg residue in place of $C y s$ and is expected to cause a reduction in catalytic activity. The mutations A 53S, H137R, $\mathrm{S} 336 \mathrm{~L}$ and $\mathrm{V} 367 \mathrm{M}$ affect residues located far from the active site and as such may have relatively little effect on catalysis. The mutations H 137R and S336L are not predicted to alter the structure or stability of glucokinase and the mechanism by which they cause 
MODY is unclear. H owever, since they are located on the surface of the glucokinase molecule, they could alter its interactions with other proteins such as the glucokinase regulatory protein [32]. The effects of these mutations on glucokinase structure and function must now be examined directly by expressing recombinant mutant glucokinase and measuring its kinetic properties, thermal stability, and interactions with other molecules. Change in any of these three aspects of the behaviour of glucokinase may affect its activity in vivo and result in M ODY $[21,27,31]$.

The study of 260 glucokinase-deficient subjects from 42 families with 36 different mutations demonstrates that this form of NIDDM is characterized by a relatively mild hyperglycaemia, with less than $50 \%$ of subjects presenting with overt diabetes. Interestingly, we have observed that $65 \%$ of the glucokinase-deficient subjects classified as having overt diabetes according to the W.H.O. diagnostic criteria fulfilled the 2-h criterium only and had fasting plasma glucose values lower than $7.8 \mathrm{mmol} / \mathrm{l}$. Thus, decompensation of the postprandial hyperglycaemia rather than an increase in the fasting glucose levels seems to be associated with the transition from impaired glucose tolerance to overt diabetes in these subjects. The observation of decreased net glycogen synthesis and increased rates of gluconeogenesis following meals in glucokinase-deficient subjects, underscores the key role of the liver and of mutant hepatic glucokinase, in the pathophysiology of this form of NIDDM [8].

There was no evidence in this cohort of glucokinase-deficient subjects for the well-established association of NIDDM of IGT with a cluster of risk factors for macrovascular disease including hypertension, obesity, and dyslipidaemia. The low prevalence of these other disorders is consistent with the low frequency of coronary heart disease in subjects with glucokinase-deficient diabetes, none of whom had a previous history of myocardial infarction, and only eight subjects were being treated for angina or showed electrocardiographic evidence of myocardial ischaemia. However, it should be pointed out that the majority of these subjects were not tested to exclude silent coronary heart disease which is frequent in NIDDM.

The long-term chronic hyperglycaemia present in subjects with glucokinase deficiency is not associated with increased frequency of late complications of diabetes. We have observed a lower prevalence of proliferative retinopathy, proteinuria, and peripheral neuropathy in this cohort than in other subtypes of MODY and late-onset NIDDM [19]. For instance, the risk of proliferative retinopathy in glucokinasedeficient subjects is one-third that in MODY-3 subjects, and one-eighth that of subjects with late-onset NIDD M [19]. This may be a consequence of the relatively small increase in blood glucose levels which is possibly lower than the threshold above which the risk of diabetic complications increases, and of the low prevalence of hypertension in the subjects with glucokinase-deficient diabetes.

In conclusion, hyperglycaemia associated with GCK mutations is often mild, develops during the early years of life, and is not associated with increased frequency of micro- and macrovascular complications of diabetes. These mutations are highly penetrant as nearly all affected individuals have abnormalities of glucose homeostasis. A Ithough it is clear that mutations in GCK can lead to overt diabetes, there is still a great deal that we do not know about the natural history of glucokinase-dificient diabetes, including the factors that trigger the progression from mild chronic hyperglycaemia to I G T to overt diabetes. Prospective studies of a large group of families such as those we have identified could lead to the identification of these factors, which may be genetic or environmental, and provide insight into the clinical progression of this and other forms of MODY as well as of the more common late-onset form(s) of NIDDM.

A cknowledgements. We thank D r. D.A.H anck for her helpful comments. These studies were supported by the Howard $\mathrm{H}$ ughes M edical Institute and grants from the $U$ nited States Public $\mathrm{H}$ ealth Service, the Juvenile Diabetes Foundation (J D F ), and the “M inistère de l'E ducation Nationale, de l'Enseignement Supérieur et de la R echerche" from France.

\section{References}

1. Fajans SS (1990) Scope and heterogeneous nature of M ODY. D iabetes Care 13: 49-64

2. L edermann HM (1995) I s maturity onset diabetes at young age (MODY) more common in Europe than previously assumed? L ancet 345: 648 ( $L$ etter)

3. B ell G I , X iang K S, N ewman M V et al. (1991) G ene for non insulin dependent diabetes mellitus (maturity onset diabetes of the young subtype) is linked to DNA polymorphism on chromosome 20q. Proc Natl A cad Sci USA 88: 14841488

4. Froguel $P, Z$ ouali $H$, Vionnet $N$ et al. (1993) Familial hyperglycemia due to mutations in glucokinase: definition of a subtype of diabetes mellitus. N Engl J M ed 328: 697-702

5. Vaxillaire M, Boccio V, Philippi A et al. (1995) A gene for maturity onset diabetes of the young (MODY) maps to chromosome 12q. Nature G enetics 9: 418-423

6. Velho G, Froguel $P$, Clément $K$ et al. (1992) Primary pancreatic beta-cell secretory defect caused by mutations in the glucokinase in kindreds of maturity onset diabetes of the young. $L$ ancet 340: 444-448

7. Byrne M M , Sturis J, Clément K et al. (1994) Insulin secretory abnormalities in subjects with hyperglycemia due to glucokinase mutations. J Clin Invest 93: 1120-1130

8. Velho G, Petersen K F, Perseghin G et al. (1996) Impaired hepatic glycogen synthesis in glucokinase-deficient (M ODY -2) subjects. J Clin Invest: 98: 1755-1761

9. Clément K, Pueyo ME, Vaxillaire M et al. (1996) A ssessment of insulin sensitivity in glucokinase-deficient subjects. D iabetologia 39: 82-90 
10. Z ouali H , Vaxillaire M , L esage S et al. (1993) L inkage analysis and molecular scanning of the glucokinase gene in NIDDM families. Diabetes 42: 1238-1245

11. H ager J, B lanché H, Sun F et al. (1994) Six mutations in the glucokinase gene identified in MODY using a nonradioactive sensitive screening technique. $D$ iabetes 43: 730-733

12. WH O Study Group on Diabetes Mellitus (1985) R eport. Technical Report Series no 727. World Health O rganization, G eneva

13. Stoffel M , Froguel P, Takeda J et al. (1992) H uman glucokinase gene: isolation, characterization, and identification of two missense mutations linked to early-onset non-insulindependent (type 2) diabetes mellitus. Proc Natl A cad Sci USA 89: 7698-7702

14. Blanché $\mathrm{H}, \mathrm{H}$ ager J, Sun $\mathrm{F}$ et al. (1994) Nonradioactive screening of glucokinase mutations in maturity onset diabetes of the young. Biotechniques 16: 866-875

15. K atagiri $H$, A sano $T$, I shihara $H$ et al. (1992) N onsense mutation of glucokinase gene in late onset non insulin dependent diabetes mellitus. L ancet 340: 1316-1317

16. Sakura H, E to K, K adowaki H et al. (1992) Structure of the human glucokinase gene and identification of a missense mutation in a Japanese patient with early-onset non insulin dependent diabetes mellitus. J Clin E ndocrinol M etab 75: 1571-1573

17. Cooper D N, K rawczak M, A ntonarakis SE (1995) The nature and mechanisms of human gene mutations. In: Scriver $C R$ (ed) The metabolic and molecular basis of inherited disease. M cG raw-H ill, N ew Y ork, pp 259-291

18. E Ibein SC, H offman M, Q in H, Chiu K, Tanizawa Y, Permutt MA (1994) Molecular screening of the glucokinase gene in familial type 2 (non-insulin-dependent) diabetes mellitus. D iabetologia 37: 182-187

19. Velho G, Vaxillaire M , B occio V, Charpentier G, Froguel P (1996) D iabetes complications in NID D M kindreds linked to the MODY -3 locus on chromosome 12q. Diabetes Care 19: $915-919$

20. M aioli M, B ertini C, M aioli M et al. (1996) A new missense mutation in the glucokinase gene in a Sardinian M ody family. Diabetes 45 [Suppl 2]: 78A (A bstract)

21. Gidh-Jain M, Takeda J, X u LZ et al. (1993) Glucokinase mutations associated with non insulin dependent (type 2) diabetes mellitus have decreased enzymatic activity: implications for structure/function relationships. Proc Natl A cad Sci U SA 90: 1932-1936
22. D ussoix P, Z ahnd G, Iynedjian PB, Tiercy J -M , Spinas G A, Philippe J (1995) Diagnosis of diabetes in the young. Diabetologia 38 [Suppl 1]: A 60 (A bstract)

23. Stoffel M, Patel P, Lo Y M D et al. (1992) M issense glucokinase mutation in maturity-onset diabetes of the young and mutation screening in late-onset diabetes. $\mathrm{N}$ ature $\mathrm{G}$ enetics 2: 153-156

24. Stoffel M, B ell KL, B lackburn CL et al. (1993) Identification of glucokinase mutations in subjects with gestational diabetes mellitus. D iabetes 42: 937-940

25. Shimada F, Makino H, H ashimoto N et al. (1993) Type 2 (non-insulin-dependent) diabetes mellitus associated with a mutation of the glucokinase gene in a Japanese family. D iabetologia 36: 433-437

26. N akamura M, House DV, Winter WE (1996) N ovel mutations in the glucokinase (GCK) genes of a patient with atypical diabetes mellitus (A DM) of A frican A mericans. D iabetes 45 [Suppl 2]: 77A (A bstract)

27. Takeda J, G idh-Jain M , X u L Z et al. (1993) Structure/function studies of human glucokinase: enzymatic properties of sequence polymorphism, mutations associated with diabetes, and other site-directed mutants. J Biol Chem 268: $15200-15204$

28. X u L Z, Z hang W, Weber IT, H arrison RW, Pilkis SJ (1994) Site-directed mutagenesis studies on the determinants of sugar specificity and cooperative behavior of human beta cell glucokinase. J Biol Chem 269: 27458-27465

29. Pilkis SJ, Weber IT, H arrison RW, B ell GI (1994) G lucokinase: structural analysis of a protein involved in susceptibility to diabetes. J Biol Chem 269: 21925-21928

30. St. Charles R S, H arrison RW, B ell G L, Pilkis SJ, Weber IT (1994) Molecular model of human beta-cell glucokinase built by analogy to the crystal structure of yeast hexokinase b. D iabetes 43: 784-791

31. L iang Y, K esavan P, Wang L Q et al. (1995) Variable effects of maturity onset diabetes of youth (MODY)-associated glucokinase mutations on substrate interactions and stability of the enzyme. B iochem J 309: 167-173

32. Veiga da C unha M, Courtois S, M ichel A, G osselain E, Van Schaftingen $E$ (1996) A mino acid conservation in animal glucokinases: identification of residues implicated in the interaction with the regulatory protein. J Biol Chem 271: 6292-6297 